\title{
Splenic Infarction as a Rare Cause of Chest Pain
}

\author{
Murat Koyuncu' ${ }^{1}$ Şenol Kadir Köstekci², Derya Öztürk³ ${ }^{3}$ Ertuğrul Altınbilek ${ }^{3}$, Meryem Okay ${ }^{3}$, Nihat Ekinci ${ }^{4}$ \\ 'Department of Emergency Medicine, Karabük University Faculty of Medicine, Karabük, Turkey \\ ${ }^{2} \mathrm{Clinic}$ of Emergency Medicine, Karabük Training and Research Hospital, Karabük, Turkey \\ ${ }^{3}$ Clinic of Emergency Medicine, Şişli Hamidiye Etfal Training and Research Hospital, İstanbul, Turkey \\ ${ }^{4}$ Department of Anatomy, Karabük University Faculty of Medicine, Karabük, Turkey
}

\begin{abstract}
This report reviews literature on splenic infarction. It also describes the case of a 27-year-old female who was bedridden because of a muscular disease and who was admitted to the emergency department with chest pain. She experienced continuous squeezing and compressing pain, which originated from the lower left hemithorax and radiated to the left axilla. A splenic infarct was detected after $24 \mathrm{~h}$ follow-up in the emergency room. Emergency physicians should keep in mind that chest pain originating from the lower left thorax and radiating to the left shoulder can be a sign of splenic infarction. (Eurasian J Emerg Med 2015; 14: 154-6)
\end{abstract}

Keywords: Chest pain, emergency department, splenic infarction

\section{Introduction}

Splenic infarction is a rare clinical condition that occurs as a complication of other diseases, and it has no specific signs (1). We highlight a case of splenic infarction with a complaint of chest pain and also review literature on this condition.

\section{Case Presentation}

A 27-year-old female who was bedridden because of a muscular disease was admitted to the emergency department with chest pain radiating to the axilla. The patient complained of nausea and warm sweating but not vomiting. Her family had no history of coronary artery disease. Loss of strength in the lower extremities began approximately 15 years ago and increased with time and advanced to the upper extremities. She was told that the disease could be muscular dystrophy or amyotrophic lateral sclerosis; however, no definitive diagnosis was made. The patient was bedridden for 10 years. She underwent a tracheostomy opening 2 years ago and was connected to a mechanical ventilator.
In the patient's physical examination, the lung sounds were normal; there were no rales or rhonchi. There were rhythmic heart sounds and no additional sound or murmur. The abdomen was puffed up, no rigidity, no precision or rebound. Spasticity and paraplegia were present on the lower extremities, but the patient could lift her arms to the shoulder level. Electrocardiography (ECG) revealed a sinus rhythm, and the heart rate was $98 / \mathrm{min}$. No additional pathology was seen in the direct standing abdominal and chest radiographs. Ultrasonography revealed no abnormality. The levels of cardiac enzymes, amylase, lipase, and liver enzymes were also normal.

The first probable diagnoses were acute coronary syndrome and peptic ulcer. In the emergency department, she received aspirin 300 $\mathrm{mg}, 6000$ anti-XA, $0.6 \mathrm{~mL}$ enoxaparin, proton pump inhibitor, and an antispasmodic. However, her pain had not decrease. She followed for $24 \mathrm{~h}$ with serial ECG and cardiac enzymes on the emergency services as no pick up was reported.

Contrast-enhanced abdominal computed tomography was taken because the patient's pain persisted, and a splenic infarct was detected (Figure 1,2). The patient was hospitalized in the general surgery department.

Correspondence to: Şenol Kadir Köstekci e-mail: drkostekci67@hotmail.com 


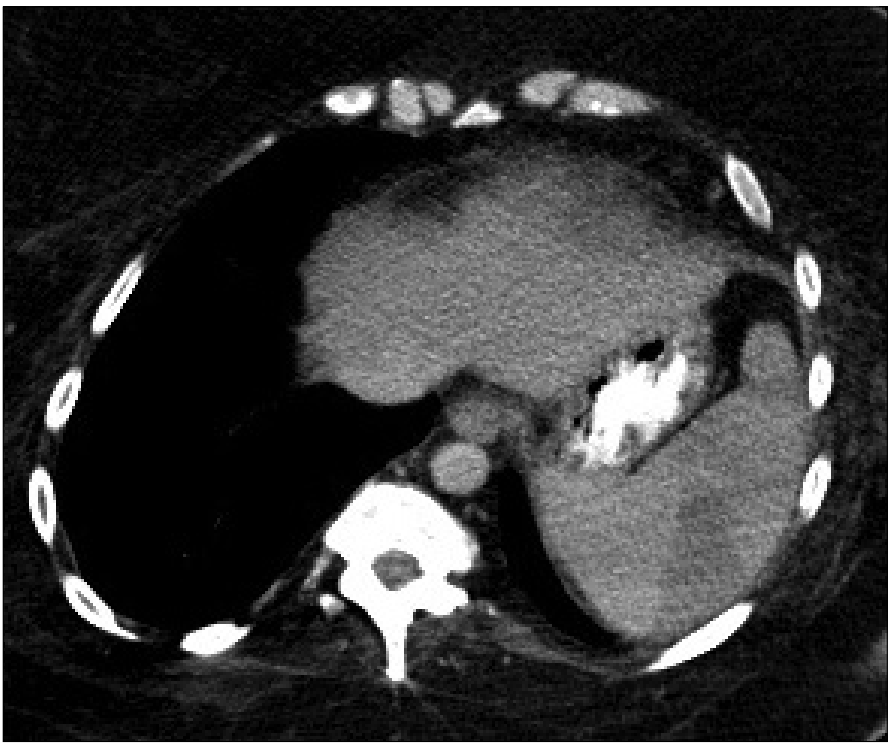

Figure 1. Splenic infarction in axial section of abdominal computed tomography

\section{Discussion}

Chest pain is often encountered as an important health problem during daily emergency practice. Chest pain at the age of over 15 years is the first level complaint in the United State of America; applicants to emergency services reach 6.4 million annually. Despite the absence of statistical data on emergency room visits, it is correct to say that there is a similar situation in our country. No life-threatening situation is detected in the vast majority of these patients, and they are kept under observation in the emergency department or unit to determine if they have any serious pathology. However, 2-5\% of acute coronary syndrome cases cannot be diagnosed in the emergency department, and it is reported that heart attack cases that cannot be identified by emergency services comprise $20-39 \%$ of malpractice suits. Emergency physicians should give priority to life-threatening diseases such as acute coronary syndrome, pulmonary embolism, and aortic dissection. The overall approach to the differential diagnosis of chest pain is to evaluate the contrast-enhanced computed tomography of the chest for aortic dissection and pulmonary embolism. If the result is negative, serial cardiac enzyme level and ECG monitoring should be done, and patients' vital signs should be continuously monitored. Patients should be followed-up in hospital emergency rooms because there are no specific units to follow-up chest pain. If the results are negative, the cardiac stress test should be applied (2-5).

Splenic infarction is a rare clinical diagnosis before death. When we analyze literature, we only find case reports on splenic infarction that generally occurs as a complication of other diseases. Splenic infarction is mostly found during cases of the most common hematologic diseases, including sickle cell anemia, bacterial endocarditis, hematologic malignancy, cardiac embolism, hypercoagulability, splenic vascular diseases, myelofibrosis, sarcoidosis, amyloidosis, pancreatitis, collagen vascular diseases, and non-hematological neoplastic diseases. Splenic infarction has also been reported in cases of spontaneous splenic infarcts. It usually shows symptoms of abdominal pain radiating to the upper left quadrant and left shoulder (1, 6, 7). The spleen is controlled by the autonomic nervous system. Parasympathetic fibers are carried by the vagus nerve. The sympathetic

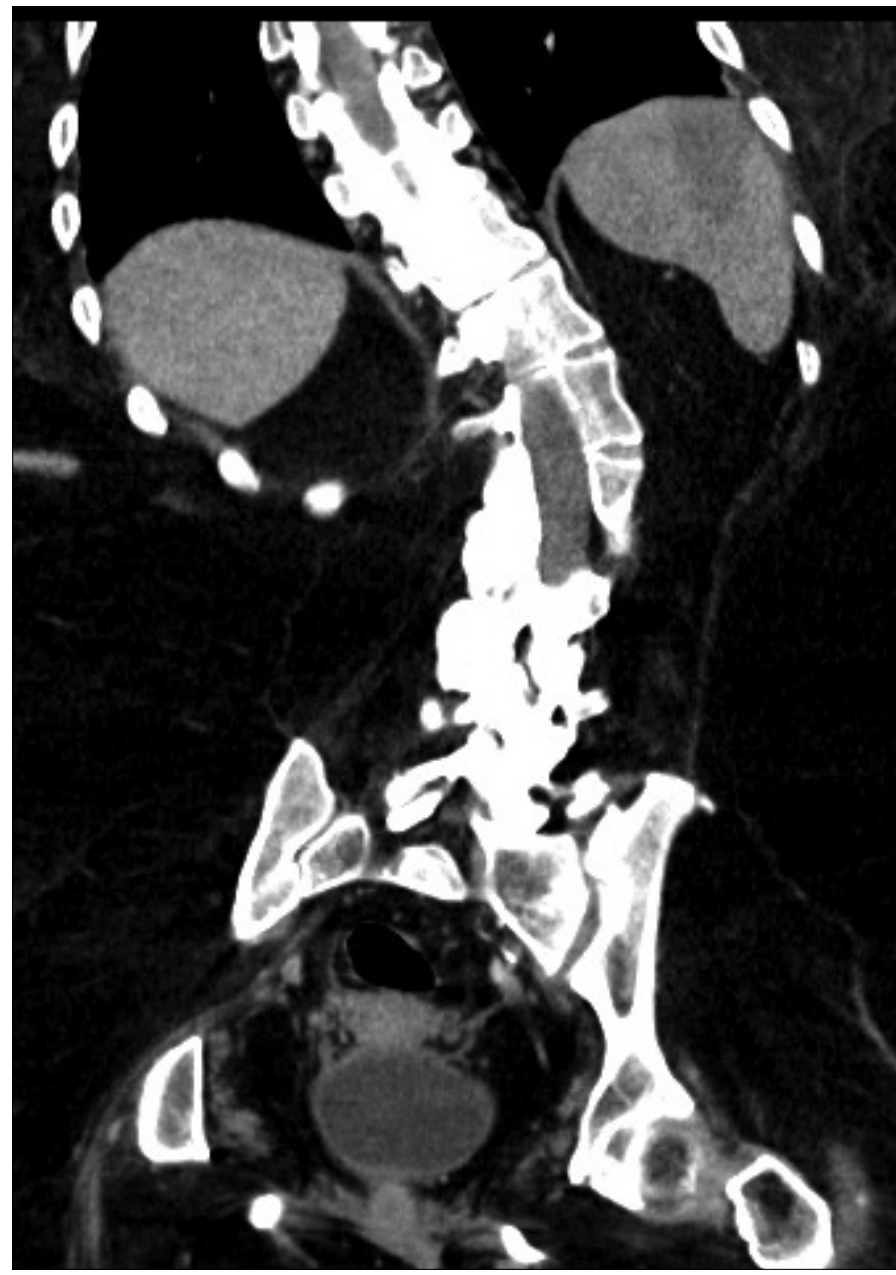

Figure 2. Splenic infarction in coronal section of abdominal computed tomography

fibers follow the splenic artery and create the celiac plexus. The celiac plexus is derived from the T5-T10 ganglionic roots. Because of this, the pain from the spleen is felt in the area between the umbilical region and the left shoulder radiating to the axilla (8). This is because the sympathetic fibers carried by the greater splanchnic nerves enter into the T5-T10 range of the spinal cord and this causes the pain.

Contrast-enhanced abdominal computed tomography plays an important role in the diagnosis of splenic infarction. The infarction cannot be directly seen by X-rays. However, after $24 \mathrm{~h}$ of infarction, ultrasonography can identify the lesion, which is called "demarcation line". Because of this, there are difficulties in the diagnosis of splenic infarction $(1,6,7)$. In our case, the diagnosis was made after $24 \mathrm{~h}$ by contrast-enhanced abdominal computed tomography.

For treatment, hydration, oxygenation, analgesics, and antiaggregants are suggested. The infarct area generally regresses in 7-14 days. Splenectomy is needed if subcapsular hematomas, splenic rupture, splenic abscess, or pseudocysts are seen; however, it is rarely necessary. In most cases, conservative treatment is enough.

\section{Conclusion}

Emergency physicians should keep in mind that chest pain originating in the left thorax and radiating to the left shoulder can be a sign of splenic infarction. 
Informed Consent: Written informed consent wasn't obtained from patient as the patient couldn't be reached.

Peer-review: Externally peer-reviewed.

Conflict of Interest: No conflict of interest was declared by the authors.

Financial Disclosure: The authors declared that this study has received no financial support.

\section{References}

1. Hatipoğlu AR, Karakaya K, Karagülle E, Demir M. Nadir görülen bir akut karın tablosu: Splenik infarkt. Ulusal Travma Acil Cerrahi Derg 2000; 6: 228-30.
2. Cimili Öztürk T, Güneysel Ö, Yeşil O, Eren Çevik Ş. Acil serviste göğüs ağrısına yeni bir yaklaşım "TripleRule-Out" BT. Eurasian J Emerg Med 2012; 11:41-7.

3. Bastarrika G, Thilo C, Headden GF, Zwerner PL, Costello P, Schoepf UJ. Cardiac $\mathrm{CT}$ in the assessment of acute chest pain in the emergency department. AJR Am J Roentgenol 2009; 193: 397-409. [CrossRef]

4. Schull M, Vermeulen MJ, Stukel TA. The risk of missed diagnosis of acute miyocardial infarction associated with emergency department volume. Ann Emerg Med 2006; 48: 647-55. [CrossRef]

5. Storrow AB, Gibler WB. Chest pain centers: diagnosis of acute coronary syndromes. Ann Emerg Med 2000; 35: 449-61. [CrossRef]

6. Antopolsky M, Hiller N, Salameh S, Goldshtein B, Stalnikowicz R. Splenic infaction: 10 years of experience. Am J Emerg Med 2009; 27: 262-5. [CrossRef]

7. Erarslan E, Bozkurt A, Yüksel I, Demir HD. Spontaneous splenic infarction in an elderly cirrhotic patient with multiple comorbidities. Turk J Gastroenterol 2012; 23: 596-8.

8. Arıncı K, Elhan A. Anatomi. İstanbul: Güneş yayınları. 2001; 106: 191-8. 